\title{
The Probabability Models for Risk of Vulnerability to STDs / HIV Infections among Pre-Marital Female Migrants
}

\author{
Shukla Uma Shankar
}

Department of Mathematics, L.B.S.S.P.G. College, Anandnagar, Maharajganj, U. P., India.

To Cite this Article

Shukla Uma Shankar, "The Probabability Models for Risk of Vulnerability to STDs / HIV Infections among Pre-Marital Female Migrants", International Journal for Modern Trends in Science and Technology, Vol. 07, Issue 01, January 2021, pp.158-161.

Article Info

Received on 28-December-2020, Revised on 06-January-2020, Accepted on 16-January-2021, Published on 26-January-2021.

\section{ABSTRACT}

The Human Immunodeficiency Virus (HIV) is the virus that causes AIDS, while many viruses can be controlled by the immune system but not a HIV virus. According to an estimate of UNAIDS (1998) although HIV prevalence rate is low (around 1 percent), the overall number of people with HIV infection to high. The majority of the reported AIDS cases have occurred in the sexually active and economically productive age group. Earlier men were main transmitters of the disease but now studies are showing that females are also transmitting the disease to males. The proposed model is tested set of data on the number of young unmarried female migrants and is satisfactory. According to the present study, the value of X $2=5.733$ with three degree of freedom at 5\% level of significance indicate that the proposed probability model fitted well to the distribution of female migrants. The estimated value of $=0.8039$ of the proportion of female migrants having at least one boy friend is very high because most at the young migrants believe that their friends watch pornographic material with us and they are more vulnerable to STDs and HIV/AIDs. The present study states that the probability of closed boyfriends attached with the young unmarried female migrants is $p=0.4400$ which is also approaching to fifty percent.

Key words: HIV-infection; Migrant; Pre-marital female; Probability-model.

\section{INTRODUCTION}

In India, it is well known the females have been participating equally as males now days, women have started taking up professional roles and they are now entering new fields such as administration, science, technology, medicine, journalism and etc. We all know that India is a male dominated country, but we should remove this world from our dictionary. Historically females are totally dependent on the males(Mishra, 2020). Now, we see that females have been migrating on their own irrespective of their marital status(Anderson and May, 1979). The question arises, why do we need such study? Answer is simple that STDs and HIV/AIDs are increasing. It is not a particular answer of this question. It is major problem of world and not of India. HIV/AIDs is not clearly related to female migrants, it is related to male migrants also, but somehow related to migrants (Reddy, 2004). A study of 120 samples of HIV/AIDs infection people was taken from Sri Sunderlal Hospital, Banaras Hindu 
University, India; the study reported that about $70 \%$ of them were migrants. Now (Jain, et. al., 2007) National AIDs Control Organization (NACO) estimated around 0.6 million HIV infections in 2002. They also estimated that between 3.8 and 4.5 million Indian were women and young people.

According to an estimate of UNAIDS (1998) although HIV prevalence rate is low (around 1\%), the overall number of people with HIV infection to high, The majority of the reported AIDS cases have occurred in the sexually active and economically productive age group. Earlier men were the main transmitters of the disease but now studies are showing that females are also transmitting the disease to males, A study conducted among 379 $\mathrm{HIV} /$ infected people in 1971, reported in the journal of the American Medical Association, observes an evidence of female-to-male transmission.

The real world phenomenonindicates distinct type of female migration(Fawcett et. al, 1984). Many middle and upper middle class women migrate to cities for improving their educational credentials and also to get suitable employment apparently in a quest for social advancement and also to enhance their status in the marriage market. Among the semi-literate, young girls migrating to towns/cities to work in export Gujarat are subject to various forms of hardship and exploitation at the hands of their superiors(Saradamani, 1995). Among females, the proportion of migrant and non-migrant workers in white-collar jobs was almost similar in 1971 but the same became smaller in 1991 than that of the non-migrant workers. There are more migrant women than the non-migrant women in the category of blue-collar jobs.A study conducted by Dholakia and Dholakia (1978) for 20 major Indian states showed that per capita income, average size of households and overall literary rates were the main factors explaining the variations in female participation rates across the states.

A model is a symbolic and simplified presentation of reality, which aids in the patterning of observed behaviour(Spear, 1974). Model can be clarified in to two categories as deterministic and stochastic. The deterministic models assumes a function between their input and output variables, whereas in stochastic models the input variables are treated as probabilistic distribution and their relation between the input and output variables are left to probability (Sarin, 1993) Formulation of models and their application is becoming very important in the recent times due to its usefulness and applicability in both natural and social science(Hugo, 2000).

The objective of the present work to proposed probability model based on the above studies and applied to risk for sexually transmitted infections of HIV transmission or unwanted pregnancies due to change in sexual behaviour of single female migrants(Reddy, 1986). They have wanted to make different close boyfriendsand most of them have been taking interest to go out with friends for movies or drama or to restaurants or hotels, while some of them go to night clubs, discos, bars, pubs or attend late nigh parties(Brauder and Castillo-Chavez, 2001).

The Human Immunodeficiency Virus (HIV) is the virus that causes AIDS, while many viruses can be controlled by the immune system but not a HIV virus. According to an estimate of UNAIDS (1998) although HIV prevalence rate is low (around 1 percent), the overall number of people with HIV infection to high. The majority of the reported AIDS cases have occurred in the sexually active and economically productive age group. Earlier men were main transmitters of the disease but now studies are showing that females are also transmitting the disease to males. A study conducted among $8379 \mathrm{HIV} /$ infected people in 1991, reported in the journal of the American Medical Association, observes an evidence of female-to-male transmission. In India, it is well known females have been participating equally as males now days, Women have started taking up professional roles and they are now entering new field such as administration science, technology, medicine, journalism etc. We all know that Indian is a male dominated country, but we should remove this word from our dictionary, historically, females are totally dependent on the males, now we see that females have been migrating on their own irrespective of their marital status, the question arises why do we need such study? Answer is simple that STDs and HIV/AIDs are increasing. It is not particular answer of this question. It is major problem of world and not of India. HIV/AIDs is not clearly related to female migrants, it is related to male migrant also, but somehow related to migrant (Reddy, 2004). A study of HIV/AIDS infected people was taken from Sri Sunder Lal Hospital BHU. India, the study reported that about 70 percent of them were 
migrants in which 39 percent were women. The epidemic continues to shift towards women and young people(Keeling and Rohani, 2007).

A model uses mathematical (deterministic and probabilistic) languages to describe a system. Models are used particularly in the natural sciences and engineering and social science disciplines(Grundmann and Hellriegel, 2006). Model in the process of creating a mathematical representation of some phenomenon in order to gain a better understanding of that phenomenon (Sarin, 1993). In view of this serious fact of the HIV/AIDs continue to shifted towards to female and young people, the objective of the present works is to be develop two probability models for premarital female migrant workers having number of closed boyfriends and they are vulnerable of STDs/HIV transmission(Terrink, 1995).

\section{Proposed Probability Model}

The proposed probably model for the number of closed boyfriendsto describe the distribution of single premarital female migration, which based on the following assumption:

(1) Let a be the proportion of female migrants having at least one closed boyfriends.

(2) Number of close boyfriend attached with the female migrants follows a displaced geometric distribution (Madhi, 2002).

(3) Let $p$ be the probability of close boyfriend attached with premarital female migrants, they are more vulnerable of STD/HIVs infections.

Under the above assumptions, the proposed probability model for the number of close boyfriend $\mathrm{X}$, is given by

$$
\begin{array}{ll}
\mathrm{P}[\mathrm{X}=0]=1-\alpha, & \mathrm{K}=0 \\
\mathrm{P}[\mathrm{X}=\mathrm{K}]=\alpha \frac{p q^{K-1}}{1-q^{T}} & \mathrm{~K}=1,2 \ldots \ldots . \mathrm{T}
\end{array}
$$

\section{Estimation OF PARAmeters}

The proposed model involves three parameters, $\alpha$, $\mathrm{p}$ and $\mathrm{T}$, After taking maximum value of $\mathrm{T}$, the rest two parameters $\alpha, p$ are estimated by method of moment, by taking zeroth cell and the theoretical mean to their observed values,

$$
\begin{aligned}
& 1-\alpha=\frac{f_{0}}{f} \\
& \text { Mean }=\alpha\left[\frac{1}{P}-\frac{T q^{T}}{1-q^{T}}\right]
\end{aligned}
$$

\section{DATA}

The study is based on surveyed of 362 unmarried working women, less than 30 years of age in Delhi urban area, while they have wanted lavish life styles and having number rich boyfriends. Randomly selected from 12 working women's hostel in Delhi. The list of the hostels was obtained from Social Welfare Department, YW/Ca and wardens of the hostels. Details about the data are given in Jain et. al., (2007).

\section{RESULTS AND DISCUSSION}

Table-1.Given the distribution of observed and expected number of young female migrant their number of closed boyfriends. The value of $x^{2}=2.08$ with 3 degree of freedom at $5 \%$ level of significance indicates that proposed model fitted well to the 4 distribution of female migrant having at least one boy is very high because most of the young migrants believe that their friends watch pornographic materials with us. It also indicates that number of female (0.8039) migrant

one having close boyfriends. They are more vulnerable to STDs and HIV/AIDs. Probability of closed boyfriends attached with young unmarried female migrant is 0.4788 , which is also near to fifty percent.

This first sexual event has clear health implications since it mark initiation into the sexual act which if unprotected, can caries a risk of adverse outcomes such as unplanned pregnancy. HIV and sexually transmitted infections (Welling's, et al. 1994).

\begin{tabular}{|c|c|c|}
\hline $\begin{array}{l}\text { No. of closed } \\
\text { boy friends }\end{array}$ & Observed $\left(\mathrm{O}_{1}\right)$ & Expected $\left(E_{1}\right)$ \\
\hline 0 & 71 & 71.00 \\
\hline 1 & 127 & 139.34 \\
\hline 2 & 80 & 72.59 \\
\hline 3 & 55 & 47.86 \\
\hline 4 & 19 & 19.73 \\
\hline 5 & 10 & 11.48 \\
\hline Total & 362 & 362.00 \\
\hline
\end{tabular}

Table 1: Observed and Expected number of unmarried single female migrants according to their closed boyfriends.

$$
\alpha=0.8039 ; \mathrm{p}=0.4400 ; \mathrm{x}^{2}=5.733 ; \mathrm{df}=3
$$

\section{CONCLUSION}

The proposed model is tested set of data on the number of young unmarried female migrants. Works as less than 30 years of age having number of closed boyfriends. They are clearly attached with their boyfriend. Proposed model is fitted satisfactorily. Estimated values indicate an increasing the living and working conditions and 
they need adequate support should be provided to single young migrant women that might be make them vulnerable to STDs and HIV/AIDs infection.

The table II given the distribution of observed and expected number of young female migrants and their number of closed boyfriends. The value of $\mathrm{x}^{2}=5.733$ with three degree of freedom at $5 \%$ level of significance indicates that the proposed probability model fitted well to the distribution of female migrants. The estimated value of $\alpha=$ 0.8039 of the proportion of female migrants having at least one boy friend is very high because most at the young migrants believe that their friends watch pornographic material with us and they are more vulnerable to STDs and HIV/AIDs. The probability of closed boyfriends attached with the young unmarried female migrants is $p=0.4400$ which is also approaching to fifty percent.

\section{REFERENCES}

[1] G. W. Wornell, "Spread-signature CDMA: Efficient multi-user communication in the presence of fading," IEEE TrAnderson, R. M.; May, R. M. (1979): Population biology of infectious disease: Part I. Nature, 280: 361 - 7; PMID: 460412; http://dx.doi.org/10.1038/280361a0.

[2] Brauder, F. Castillo-Chavez, C. (2001): Mathematical models in population biology and epidemiology. New York: Springer-Verlag.

[3] Dholakia. B. H. and Dholakia, R.H. (1978): "Interstate Variations in Female Labour Force Participation Rate in India" Journal of Labour Economics

[4] Fawcett, J.T. Khoo, S. and Smith, P.C. (1984): "Women in the Cities of Asia: Migration and Urban Adaptation", Westview Press Boulder Colorado.

[5] Grundmann, H. and Hellriegel, B. (2006): Mathematical modeling: a tool for hospital Infection control. Lancet Infect Dis; 6(1): $39-45$.

[6] Hugo, G. (2000): "Migration and Women's Empowerment" in (ed.) H.B. Pressler and G. Sen.'Women's Empowerment and Demographic Processes oxford University Press, Oxford'.

[7] Jain, R.; Gupta, K. and Singh, A. K. (2007): "Sexual Risk Behaviour and vulnerability to HIV infection among young Migrant Women Workers in Urban India" assess on July 17,2007, http://paa2007.princeton.edu/download.aspx? Submission ID=72114.

[8] Keeling, M. J. and Rohani, P. (2007): Modeling infectious diseases in humans and animals. Princeton: Princeton University Press.

[9] Madhi. J. (2002): An Introduction to stochastic Process Chapter Weilly \& Jons, New Delhi.

[10] Mishra Surya Prakash (2020): Review on Corona Virus Disease 2019 (COVID-19):Current Status and Future Perspectives. Int. J. of Creative Research Thoughts, Vol. 8(6): 3542 - 3551, DOI: http:/doi.one/10.1729/Journal 24038.

[11] Reddy, C.R. (1986): "Changing Status of Educated Working women-A Case Study", B.R.Publishing Corporation, Delhi.

[12] Reddy, D.C.S. (2004): "Prevention of HIV/AIDS in Uttar Pradesh" organized by the status Innovations in Family Planning Services Agency (SIEPSA), U.P. State AIDs control
Society and the Policy Project, The Futures Group International, Agra January 29-31.

[13] Saradamani. K. (1995): Crisis in the Fishing Industry and Women's Migration : The case of Kerala in Schenk Sandbergen (ed.) "Women and Seasonal labour Migration" IDPAP Sage New Delhi, pp. 145-152.

[14] Spear. Jr. A. (1974):Residential satisfaction as an Intervening variable in Residential Mobility 'Demography', Vol. II, pp. 173-188.

[15] Sarin, D. (1993): "Some Mathematical Models for the Relationship among Migration"Fatality and population growth. Ph.D. Thesis in Statistics BHU India.

[16] Terrink Rensj (1995): 'Migration and its impact on Khandeshi women in the sugarcane Harvest' in (ed.) Schenk Sandbergen, "'Women and Seasonal Labour Migration", IDPAD Sage New Delhi.

[17] UNAIDS (1998):"Migration and AIDS". International Migration, Vol. 36, No. 4 : 445-466.

[18] Willings, K., J. Field, A. Johnson, S.J. Wardsworth (1994): "Sexual behavioural and Lifestyle in Britain, The national survey of sexual attitudes and lifestyle" Penguing Books Ltd., London, England. 